\title{
CHARACTERIZATION OF THE ADHESION OF FLAVOBACTERIUM COLUMNARE (FLEXIBACTER COLUMNARIS) TO GILL TISSUE
}

\section{Decostere, Annemie*1, Haesebrouck, Freddy1, Van Driessche, Edillbert ${ }^{2}$, Charlier, Gerard ${ }^{3}$ and Ducatelle, Richard ${ }^{1}$}

\author{
I Laboratory of Veterinary Bacteriology and Mycology and Laboratory of Veterinary Pathology \\ Faculty of Veterinary Medicine, University of Gent, Salisburylaan 133, 9820 Merelbeke, Belgium, 2 Laboratory of \\ Protein Chemistry, Vrije Universiteit Brussel, Paardenstraat 65, 1640 Sint-Genesius-Rode, Belgium, ${ }^{3}$ Veterinary \\ Agrochemical Research Institute (CODA), Groeselenberg 99, 1180 Brussels, Belgium
}

Flavobacterium columnare is an important cause of gill and skin disease in freshwater fish species, often causing high mortality. In previous studies, virulence of $F$. columnare was correlated with the ability to adhere to gill tissue (Decostere et al., 1998; 1999). To gain insight into the factors responsible for adherence, a gill perfusion model was used. Bacterial cells of the high virulence strain AJS 1 were exposed to various treatments, after which they were added to the organ bath of an isolated gill arch and adherence to the gill tissue assessed. Adherence capabilities were significantly reduced following incubation of the bacteria with sodium metaperiodate and specific carbohydrates. Incubation of the bacteria with trypsin and pronase did not significantly inhibit adherence. The binding sites for $F$. columnare on gill tissue were also partially characterized. Treatment of the gill with sodium metaperiodate reduced adhesion but treatment with pronase or trypsin did not, indicating that the major component of the receptor is of carbohydrate nature. Adherence ability of the bacteria correlated well with their hemagglutination capacity. Higher hemagglutination titers were obtained with the highly virulent strain AJS 1 than with strain AJS 4, a strain with low virulence and low adherence capacity. Hemagglutination was insensitive to pronase and trypsin treatment but was inhibited after incubation of the bacteria with specific carbohydrates and sodium metaperiodate and, following heat treatment. Transmission electron microscopy (TEM) revealed that the high virulence strain exhibited a much thicker capsule than did the low virulence strain. TEM also demonstrated the loss of the capsule of the high virulence strain after treatment of the bacterial cells with heat and sodium metaperiodate. These results indicate that a lectin-like carbohydrate-binding substance in the capsule is responsible for the attachment of $F$. columnare to the gill tissue.

Decostere et al. 1998. Veterinary Microbiology 62:35-45; Decostere et al. 1999. Journal of Fish Diseases $22: 1-11$ 